\title{
Microwave Measurements of Dielectric Properties of Zinc Oxide at High Temperature
}

\author{
Thoria A. Baeraky, \\ Faculty of Science, Physics Department, King Abdulaziz University, \\ Jeddah, Saudi Arabia.
}

The dielectric properties of zinc oxide material are measured at high temperature and in microwave frequency ranges. The real and the imaginary parts of the complex permittivity are calculated using the measured shift on frequency of the full computerized cavity perturbation technique working in microwave frequency ranges, $615 \mathrm{MHz}, 1412 \mathrm{MHz}, 2214 \mathrm{MHz}, 3017 \mathrm{MHz}$, and $3820 \mathrm{MHz}$ at temperature from $25^{\circ} \mathrm{C}$ to $2000{ }^{\circ} \mathrm{C}$ in step of $50{ }^{\circ} \mathrm{C}$. The temperature and frequency-dependent electrical conductivity, $\sigma$, of zinc oxide is calculated using the complex permittivity imaginary part, $\varepsilon^{\prime \prime}$, measured in the microwave frequency and the temperature ranges of the above technique. The frequency exponent $\boldsymbol{n}$, and the activation energy, $\boldsymbol{E}_{\boldsymbol{A}}$, are determined using the calculated electrical conductivity, $\sigma$, in the same microwave frequency and the same temperature ranges.

\section{Introduction:}

Ceramics are inorganic nonmetallic materials which consist of metallic/nonmetallic compounds that are bonded primarily by ionic bonds, sometimes with covalent character. Microwave dielectric ceramics, which have high permittivity, are used as materials of microwave components such as resonator, band pass filter and duplexer. These materials received attention due to the rapid progress in microwave telecommunications and satellite broadcasting etc. [1,2]. Microwave processing of ceramics has advantages in reducing the time and temperature of processing as well as improving the homogeneity of heating. Microwave energy interact with the material at the molecular level, it rises inside the material itself, and depends on the dielectric properties of the material and on the incident microwave frequency. Microwave measurements for the dielectric properties of materials at different frequencies and different temperature can be helpful in understanding the microwave mechanism of heating [3].

E-mail: tbaerky@kaau.edu.sa 
Zinc oxide $(\mathrm{ZnO})$ is of great interest as a suitable material for high temperature, high power electronic devices either as the active material or as a suitable substrate for epitaxial growth of group III-nitride compounds With its large, direct band gap $(3.4 \mathrm{eV}$ at $300 \mathrm{~K})$ and high excitonic binding energy $(60 \mathrm{meV})$. With appropriate dopants such as aluminum and galum, it is both transparent in the visible region and electrically conductive [4, 5]. In this work, the dielectric properties of $\mathrm{ZnO}$ in microwave frequency range and high temperature will be measured by using the technique that is based on cavity perturbation theory.

\section{Experimental:}

Cavity perturbation technique was used to measure the complex permittivity of $\mathrm{ZnO}$ in microwave frequencies, $615 \mathrm{MHz}, 1412 \mathrm{MHz}, 2214$ $\mathrm{MHz}, 3017 \mathrm{MHz}$, and $3820 \mathrm{MHz}$ and at temperature from $25{ }^{\circ} \mathrm{C}$ to $2000{ }^{\circ} \mathrm{C}$. The details of this technique have been reported in [6] and will not be discussed further. Measurements are performed by measuring the resonant frequencies of the cavity with and without the sample, $f$ and $f_{o}$, respectively, and the quality factors of the cavity with and without the sample, $Q$ and $Q_{o}$, respectively. The simple perturbation formula derived by Nakamura and Furuichi [7] is based on the shift of frequency, $\Delta f$, and on the shift of the reciprocal quality factor, $\Delta(1 / Q)$. The real, $\varepsilon^{\prime}$, and the imaginary, $\varepsilon^{\prime \prime}$, parts of the complex permittivity can be calculated by using Eqs. (1) and (2).

$$
\begin{aligned}
& \varepsilon^{\prime}=2 j^{2}\left(\chi_{o n}\right) \frac{a^{2}}{b^{2}} \frac{\Delta f}{f}+1 \\
& \varepsilon^{\prime \prime}=j^{2}\left(\chi_{o n}\right) \frac{a^{2}}{b^{2}} \Delta\left(\frac{1}{Q}\right)
\end{aligned}
$$

where $\chi_{o n}$ is the root of the zero order Bessel function, $j$, of the first kind. $\boldsymbol{a}$ and $b$ are the sample and the cavity volumes respectively. The electrical conductivity $\sigma$, the activation energy, $E_{A}$, and the exponent frequency, $n$, can be calculated by substituting the measured imaginary part, $\varepsilon^{\prime \prime}$, of the complex permittivity in Eq. (3) and using the slope of Eq. $(4,5)$ respectively [8].

$$
\begin{aligned}
(\omega) & =\varepsilon_{o} \omega \varepsilon^{\prime \prime}(\omega) \\
\sigma & =A \exp \left(-E_{A} / k T\right)
\end{aligned}
$$




$$
\sigma(\omega)=A \omega^{n}
$$

where $k$ is Boltzmann's constant and $T$ is the absolute temperature (K).

\section{Results and Discussion:}

White powder Zinc Oxide of density $1.1 \mathrm{~g} \mathrm{~cm}^{-3}$ was selected to study its electrical characteristics in microwave frequency range and at high temperature. Holder sample is a special silica tube, stand to temperature up to $2000{ }^{\circ} \boldsymbol{C}$. The tube of $3 \mathrm{~mm}$ in diameter was filled by $\mathrm{ZnO}$ to hold it during the measurements between the cavity and the furnace. The variation of the complex permittivity real part with the changing of frequency and temperature is shown in Fig. (1).

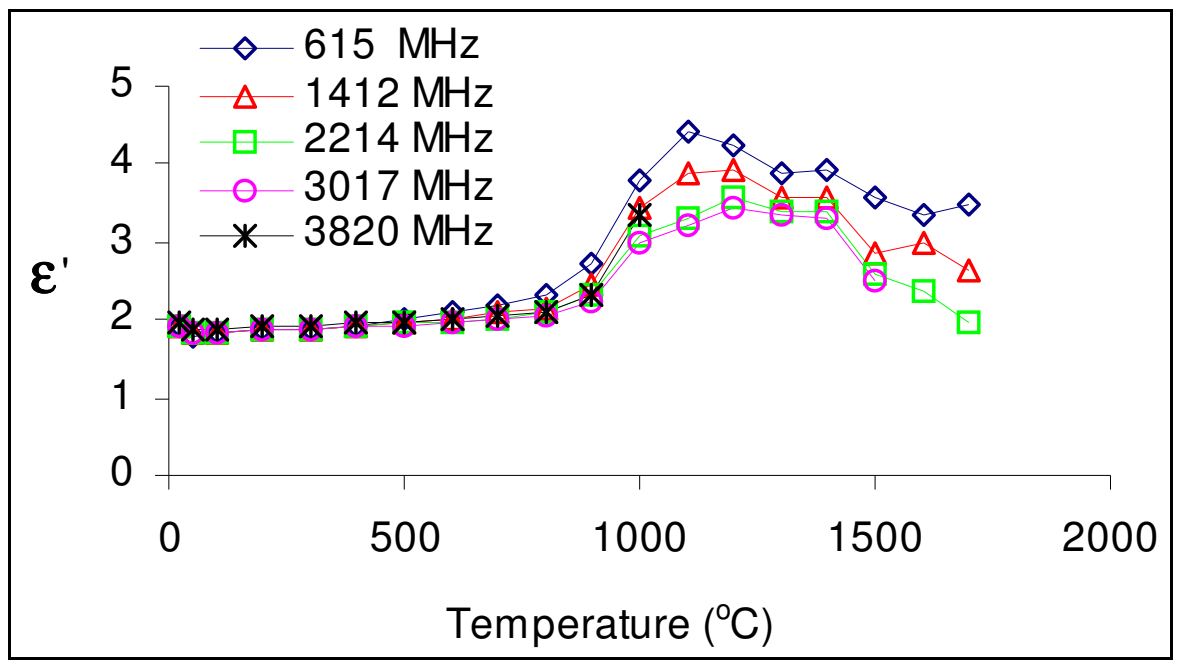

Fig. (1): The complex permittivity real part.

The variation of the complex permittivity real part, $\varepsilon^{\prime}$, with the changing in frequency and temperature appeared when the temperature reached $600{ }^{\circ} \mathrm{C}$. The complex permittivity real part, $\varepsilon^{\prime}$, varied from 1.9 to 2.1 values in temperature range from 25 to $600{ }^{\circ} \mathrm{C}$ at all the frequency ranges, $615 \mathrm{MHz}$, $1412 \mathrm{MHz}, 2214 \mathrm{MHz}, 3017 \mathrm{MHz}$ and $3820 \mathrm{MHz}$. . However, at $615 \mathrm{MHz}, \boldsymbol{\varepsilon}^{\prime}$ increased to the maximum value, 4.43 , at $1100{ }^{\circ} \mathrm{C}$ and decreased to 3.5 at 1700 ${ }^{\circ} \mathrm{C}$. While at $1412 \mathrm{MHz}, 2214 \mathrm{MHz}, 3017 \mathrm{MHz}$, and $3820 \mathrm{MHz}$, the maximum appeared at $1200{ }^{\circ} \mathrm{C}$ whereas the peaks decrease with frequency increasing. 
The variation of the complex permittivity imaginary part, $\varepsilon^{\prime \prime}$, with the changing of frequency and temperature is shown in Fig. (2). In this Figure, $\varepsilon^{\prime \prime}$ is almost consistent at all the frequency ranges and starts to increase when the temperature reached $600{ }^{\circ} \mathrm{C}$. The complex permittivity imaginary part, $\varepsilon^{\prime \prime}$, has two maxima. The first maximum appeared when the temperature reached $1100{ }^{\circ} \mathrm{C}$ at all the given frequencies; the second one appeared when the temperature reached $1500{ }^{\circ} \mathrm{C}$, while the other maximum for $615 \mathrm{MHz}$ shifted to $1600^{\circ} \mathrm{C}$.

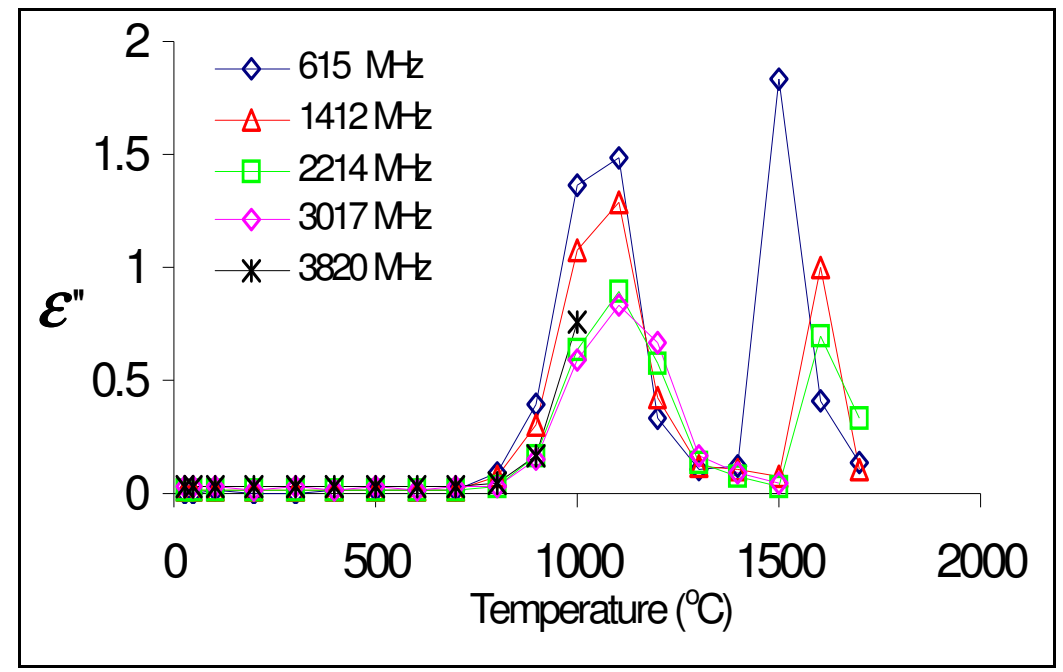

Fig. (2): The complex permittivity imaginary part.

Figure (3) shows the variation of the electrical conductivity, $\sigma$, of $\mathrm{ZnO}$ with the changing of temperature in microwave frequency ranges, $615 \mathrm{MHz}$, $1412 \mathrm{MHz}, 2214 \mathrm{MHz}, 3017 \mathrm{MHz}$, and $3820 \mathrm{MHz}$. Two maxima values of the electrical conductivity of $\mathrm{ZnO}$ are observed near $1100{ }^{\circ} \mathrm{C}$ and $1500{ }^{\circ} \mathrm{C}$ at the frequencies $615 \mathrm{MHz}$ and $1412 \mathrm{MHz}$ only. But for the other frequency ranges the electrical conductivity is very small and seems to be constant during the measurements. Fig. (4) shows the variation of the activation energy, $\boldsymbol{E}_{\boldsymbol{A}}$, of $\mathrm{ZnO}$ with the changing of temperature in the same microwave frequency ranges. The activation energy starts to increase at temperature close to $600{ }^{\circ} \mathrm{C}$ and there are peaks at all the frequency values, $615 \mathrm{MHz}, 1412 \mathrm{MHz}, 2214 \mathrm{MHz}, 3017 \mathrm{MHz}$, and $3820 \mathrm{MHz}$, when the temperature reached $1100{ }^{\circ} \mathrm{C}$ and higher. The peak heights increase with frequency increasing. The temperature dependence of the frequency exponent, $n$, in Eq. (5) illustrated in Fig. (5). The results show that $\boldsymbol{n}$ decreased with the temperature and frequency increasing in temperature range from 600 to $1000{ }^{\circ} \mathrm{C}$. The peaks appeared when temperature reached $1300{ }^{\circ} \mathrm{C}$. 


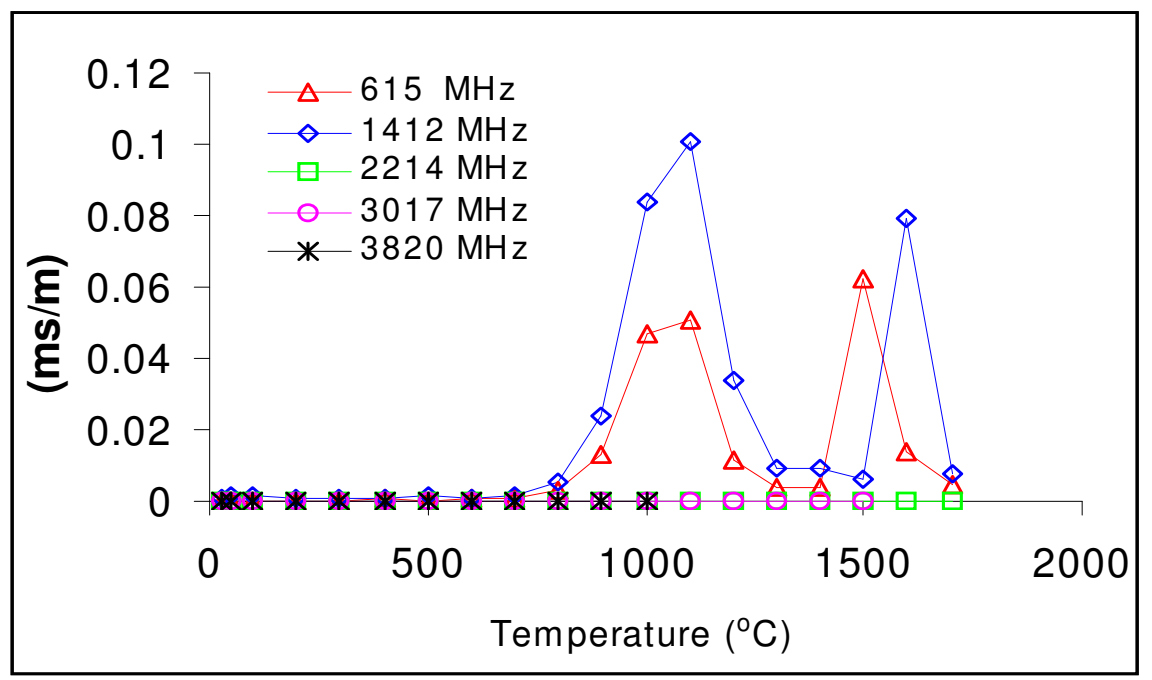

Fig. (3): The electrical conductivity of $\mathrm{ZnO}$.

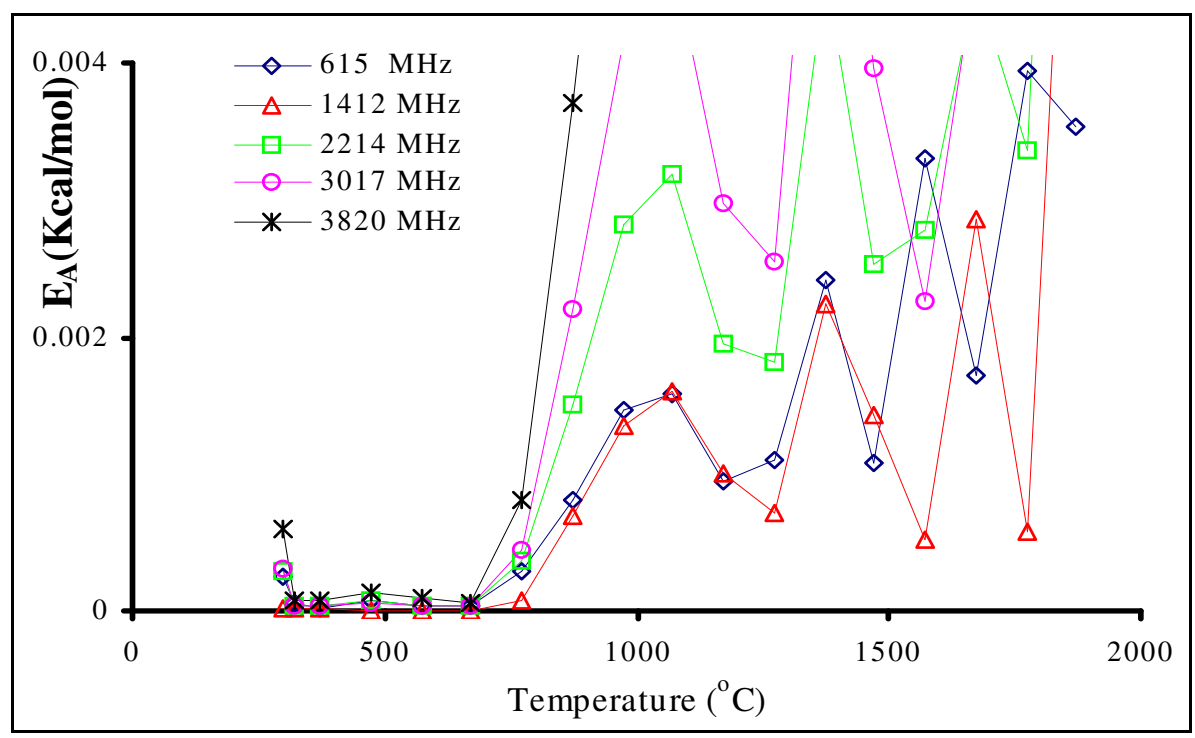

Fig. (4): The activation energy of $\mathrm{ZnO}$. 


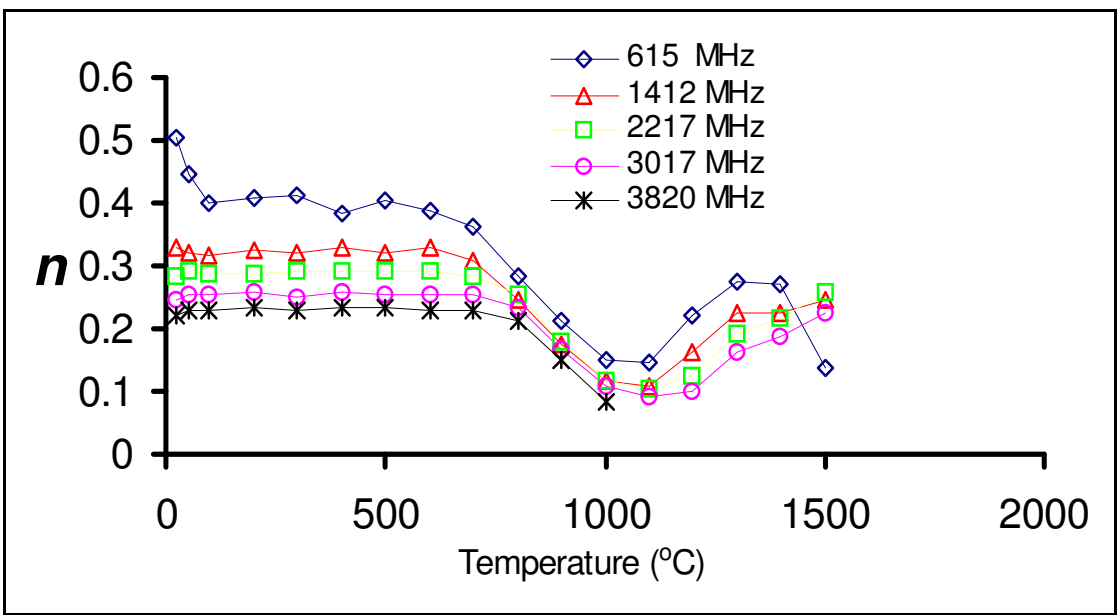

Fig. (5): The temperature dependence of the frequency exponent, $n$, of $\mathrm{ZnO}$.

\section{Conclusion:}

The complex permittivity measurements of $\mathrm{ZnO}$ in microwave frequency ranges, $615 \mathrm{MHz}, 1412 \mathrm{MHz}, 2214 \mathrm{MHz}, 3017 \mathrm{MHz}$, and 3820 $\mathrm{MHz}$, and high temperature up to $2000{ }^{\circ} \mathrm{C}$, show that the microwave transparent and the electrical resistivity of this material are very high such that they have a relatively small change during the measurements when the temperature reached $500{ }^{\circ} \mathrm{C}$. At the temperature $1100{ }^{\circ} \mathrm{C}$ and $1500{ }^{\circ} \mathrm{C}, \mathrm{ZnO}$ seams to be microwave absorpting material.

\section{Refrences:}

1. Ji-Won Choi, Jong-Yoon HA, Chong-Yun KanG, Seok-Jin Yoon, HyunJai KIM and Ko Hyun Yoon, Jpn. J. Appl. Phys. 39, 5923 (2000).

2. C.E. Holcombe and N. L. Dykes, J. Am. Ceram.Soc. 21, 375 (1991)

3. Rustum Roy, D. Agrawal, J.P. Cheng, and M. Mathis, J. Am. Ceram. Soc. 80, 3 (1997).

4. B. N. Mbenkum, N. ashkenov, M. Schubert, M. Lorenz, H. Hochmuth, D. Michel, and M. Grundmann, J. Appl. Phys. Letters 86, 091904-1 (2005).

5. S. K. Nandi, S. Chatterjee, S. K. Samanta, G. K. Dalapati, P. K. Bose, S. Varma, Shivprasad Patil and C. K. Maiti, Bull. Mater. Sci. 26, (4), 365(2003).

6. T. A. Baeraky, Egypt. J. Solids 25, 263 (2002).

7. E. Nakamura and J. Furuichi, J. Phys. Soc. Japan. 15, 1955 (1960).

8. D. W. Strickler, W. G. Carlson, J. Am. Ceram. Soc. 47, 122 (1984). 